\title{
A Clinical Study of 100 Cases of Obstructed Labour and Its Fetomaternal Outcome
}

\author{
Dr. Ashmita Kiran \\ Assistant Professor \\ Department of Obstetrics and Gynaecology, Katihar Medical College, Bihar, India
}

Dr. Rakesh Ranjan Singh

Associate Professor

Department of Anaesthesia, Katihar Medical College, Bihar, India

Dr. Anant Narayan Sinha (Corresponding author)

Associate Professor, Department of Physiology

Veer Chandra Singh Garhwali Government Institute of Medical Science and Research

Srinagar, Uttarakhand (India)

E-mail: ansinha1973@yahoo.in

Received: May 3, 2015 Accepted: May 20, 2015

doi:10.5296/jbls.v6i2.7564 URL: http://dx.doi.org/10.5296/jbls.v6i2.7564

\begin{abstract}
Prevention is the foundation stone of safe and successful obstetrics. Many factors responsible for disastrous outcome of obstructed labour can be nullified to a large extent by sustained and planned effort, improvement of socio economic condition and educational standard, awareness of antenatal and internal care, availability of medical facilities in remote areas and health education with advice of family welfare can minimize the unfortunate outcome of OL. We studied 100 cases of obstructed labour and its fetomaternal outcome.
\end{abstract}

Key words: Cephalo-Pelvic Disproportion, Labour, Pelvis 


\section{1) Macrothink}

\section{Introduction}

Inability of foetus passing through the birth canal despite of uterine contractions is considered as obstructed labour (OL) (Gessessew and Mesfin., 2003). It is a major Cause of maternal and perinatal morbidity in developing countries (Gupta and Porwal., 2012). There are five major causes of maternal death: postpartum hemorrhage, infection, OL, hypertensive disorders and unsafe abortion (Khan et al., 2006). Premature death is not only the consequence of neglected OL, obstetric fistula (rectovaginal or vesicovaginal ) is also a major consequence of OL (Dolea and Zahr., 2003).

\section{Material and methods}

Present study was carried out on 100 patients of OL admitted in labour room of a teaching hospital. All cases of OL were studied in relation to age, parity, antenatal check-up, causes of OL, obstetrical management of OL and mode of parturition. Detailed history, general and obstetrical examinations were done. All cases were followed up till their stay in the hospital.

\section{Results}

Present observations revealed that majority were received as emergency cases (80\%) with no previous antenatal check-up. Incidence was remarkably low (20\%) in patients who had antenatal check-up. The age distribution of cases with OL showed that majority (46\%) of patients belongs to younger age group between 21-25 years (Table: 1). 86\% cases with OL admitted belong to rural areas.

Table 1. Age distribution of cases with OL

\begin{tabular}{|l|l|l|}
\hline Age group (in years) & No. of cases & Percentage \\
\hline Up to 20 & 19 & 19 \\
\hline $21-25$ & 46 & 46 \\
\hline $26-30$ & 25 & 25 \\
\hline Above 31 & 10 & 10 \\
\hline
\end{tabular}

It was observed that the incidence of OL was the maximum in primigravida (Table: 2).

Table 2. Relation of parity with cases of OL

\begin{tabular}{|l|l|l|}
\hline Parity & No. of cases & Percentage \\
\hline $0-1$ & 63 & 63 \\
\hline 2 & 14 & 14 \\
\hline 3 & 8 & 8 \\
\hline 4 & 8 & 8 \\
\hline 5 and above & 7 & 7 \\
\hline
\end{tabular}

Major etiological factor of obstructed labour in the present study was cephalopelvic disproportion (60\%) and malpresentation (37\%) (Table: 3 ). 
Table 3.

\begin{tabular}{|l|l|l|}
\hline Causes of OL & No. of cases & $\%$ \\
\hline Pelvic contraction and disproportion & 60 & 60 \\
\hline Malpresentaion and malposition & 37 & 37 \\
Shoulder & 20 & 20 \\
Deep transverse arrest & 6 & 6 \\
Brow & 1 & 1 \\
Face (Men to-posterior) & 1 & 1 \\
Impacted breech & 9 & 9 \\
\hline Misuse of oxytocin & 1 & 1 \\
\hline Hydrocephalus & 0 & 0 \\
\hline Cervical Dystocia & 1 & 1 \\
\hline Fetal ascites & 0 & 0 \\
\hline Pelvic tumors & 1 & 1 \\
\hline Twin & 0 & 0 \\
\hline
\end{tabular}

Incidence of cephalo-pelvic disproportion was greater in primi-gravida where as multi-gravida cases were observed with higher incidence of malpresentation (Figure: 1).

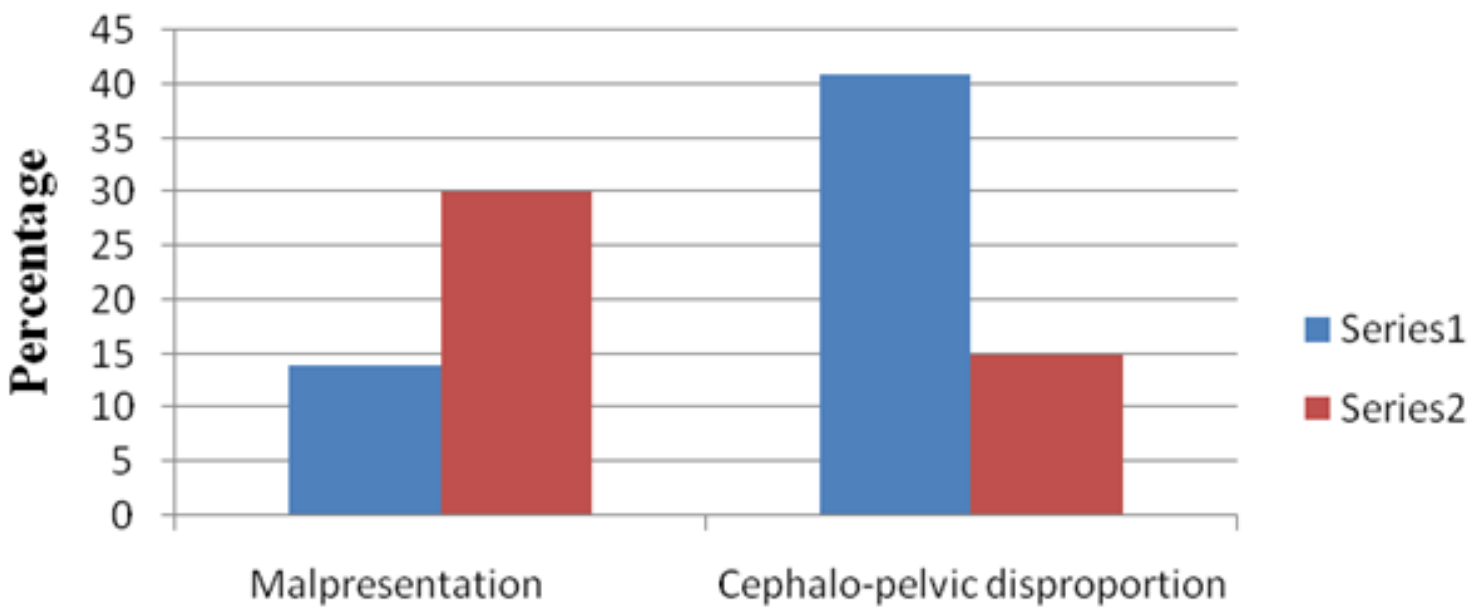

Parity

Figure 1. Parity wise distribution of malpresentation and contracted pelvis.

Most common form of management was lower segment caesarean section (LSCS) performed in 82 out of 100 cases (Table: 4). 
Table 4. Obstetrical management of OL

\begin{tabular}{|l|l|}
\hline Mode of delivery & $\%$ \\
\hline LSCS & 82 \\
\hline Forceps delivery & 7 \\
\hline Laparotomy & 6 \\
Caesarean hysterectomy & 5 \\
Repair of Rent & 1 \\
\hline Internal inversion & 0 \\
\hline Craniotomy & 3 \\
Evisceration & 2 \\
\hline
\end{tabular}

This surgery was commonly performed in 21-25 year of age group.

It is also noted that the incidence of lower segment caesarean section was high in primi-gravid $(53 \%)$ in whom pelvic contraction seems to be a major factor in promoting obstraction during labour. Destructive operation and forceps delivery were also most common in primi-gravida whereas caesarean hysterectomy performed more in multi-gravida (Table:5).

Table 5. Mode of delivery in relation to the parity of patients

\begin{tabular}{|l|l|l|l|l|l|}
\hline Parity & LSCS $\%$ & Destructive operation $\%$ & Caesarean $\%$ & Forceps delivery $\%$ & Internal version \% \\
\hline $0-1$ & 53 & 2 & 0 & 5 & 0 \\
\hline $2-4$ & 23 & 2 & 3 & 2 & 0 \\
\hline 5 and above & 8 & 1 & 2 & 0 & 0 \\
\hline
\end{tabular}

\section{Discussion}

Obstructed labour is still a burning problem in developing countries. Despite large expansion of medical services in India, the decline in OL has not been yet materialized so far. The management is a challenge for obstetrician due to wide range of complications. Even when the immediate problems like shock and rupture uterus have been dealt successfully, it leaves a tail behind in various forms. High mortality, perinatal mortality and morbidity, the ugliest urinary fistula which remains a constant reminder of the turbulent days labour in the past.

\section{Incidence of $\mathrm{OL}$}

Results of clinical study based on 100 cases of OL admitted to department of obstetrics and gynaecology are observed herewith. The high incidence of OL in present study was due to poor antenatal care, unawareness of risks of labour, lack of communication and low socioeconomic condition of the patients. Present study showed $20 \%$ cases were referred to emergency having no antenatal check up. 


\section{Relationship between OL and age}

Bhaskar Rao K (1980) reported maximum cases of OL in the age group of 21-23 years. Sarkar and paul (1990) observed majority of cases of OL in 18-21 years of age group. Gupta et al (1991) found that $72.8 \%$ of such cases to occur in age group of 20-23 years. This is due to custom of early marriage (14-16 years) among uneducated people living in rural area and high fertility in this young age group which is responsible for maximum confinement to occur at relatively younger age group and may explain the high incidence of OL in these age groups.

\section{Rural urban distribution}

Present study showed $86 \%$ patients belong to rural areas. Sarkar and paul observed $80 \%$ cases of OL belonging to rural areas. Gupta et al found $83 \%$ cases from rural areas in their study. There were very few primary health centres in the rural areas and deliveries were conducted by unskilled birth attendants. Misuse of oxytocin led to OL. Poor or insufficient health education was a major causative factor of OL.

\section{Parity incidence}

Table 2 shows that $63 \%$ cases of OL were primigravida followed by $30 \%$ in multipara and $7 \%$ in grand multipara. Sarkar and paul ${ }^{6}$ reported that primigravida constituted $45.99 \%$ cases of OL. Gupta et al ${ }^{7}$ also observed that maximum cases in primigravida $(67.15 \%)$. Although the predominance of OL was found in primigarvida in this study, the number of multipara was also high. Short stature and minor variant of contracted pelvis are still prevalent amongst ill nourished rural primigravida in our country. A greater number of involvements of multipara are explained by the facts that the secondary contracted pelvis is frequently found due to malnutrition coupled with prolonged lactation, larger size of babies in subsequent pregnancies and decreased abdominal and pelvic muscular tone causing abnormal feto-pelvis axis resulting malpresentation (Hopewood., 1982) .

\section{Etiological association of $\mathrm{OL}$}

Major etiological factors of OL in this study were cephalo-pelvic disproportion (60\%) followed by malpresentation (37\%) and misuse of oxytocin (1\%). Previous studies have also shown that cephalo-pelvic disproportion was the commonest cause of obstruction and was mostly detected in primigravida although it affected the multi gravid in a significant manner (Table-6).

\begin{tabular}{|l|l|l|}
\hline Author (s) & Cephalo pelvic disproportion \% & Malpresentation \% \\
\hline Sarkar and Paul (1990) & 69.7 & 22.8 \\
\hline Gupta et al (1991) & 50 & 38.5 \\
\hline Randhawa et al (1991) & 68 & 23 \\
\hline Kamla Jayaram (1993) & 72.3 & 24 \\
\hline Chhabra et al & 41.15 & 53.2 \\
\hline Present study & 57.33 & 36 \\
\hline
\end{tabular}


Bigger size of neonates may also predispose to cephalo-pelvic disproportion in multigravida (Rohtagi et al., 1977).

Malpresentation was the second most common cause of OL and was principally confined to multigravida. Laxity of abdominal muscles, obesity and lordosis may lead pendulous abdomen and contribute to malpresentation, malposition and ineffective bearing down effort during second stage of labour (Wendy et al., 2012). Deep transverse arrest and shoulder presentation were the main offenders causing obstruction, the less common malpresentation were face i.e. men to posterior ( 1 case), brow (1 case), impacted breech ( 9 cases) in present study.

\section{Analysis of the management of various forms of $\mathrm{OL}$}

In the present study, lower caesarean was the most common form of management done in 82 cases out of 100 (Table: 4). Caesarean rate of the present series was almost similar to the study of rohtagi et al who reported a caesarean rate of 74\%. Dutta and pal (1978) however reported a very low caesarean section (19\%). Present study showed very low incidence of destructive operation $(1.33 \%)$ which is similar to the study of rohtagi et al (1.5\%). In contrary, dutta and pal performed destructive operation in $51.8 \%$ cases. In the present series, the management was done depending upon the age, parity, general condition of the patient, the state of the uterus and presence or absence of foetal heart sounds.

Sahu and sinha (1990) emphasised the need for adopting measures specifically to economy and scientific development of the countries. In the country like India where most of the patients neglect the importance of follow up or antenatal care in subsequent pregnancies may endanger their life.

In this study most cases were emergency admissions coming from villages and from rural health centres. Considerable number of cases presented history of outside interference and were referred as a last resort when all methods of delivering them had failed outside. Management of shock, correction of dehydration, ketosis and provision of adequate antibiotics care were measures in all cases.

\section{References}

Bhaskar Rao K (1980) Maternal Mortality in India: A Co-operative Study. Journal of Obstetrics and Gynaecology. 30 (6), pp. 859-64

Wendy Moh, John M. Graham Jr., Isha Wadhawan, \& Pedro A. Sanchez-Lara (2012). Extrinsic Factors Influencing Fetal Deformations and Intrauterine Growth Restriction. Journal of Pregnancy. Vol 2012. http://dx.doi.org/10.1155/2012/750485

Chhabra S, Gandhi D, Jaiswal M (2000) Obstructed labour- a preventable entity. Journal of obstetrics \& Gynaecology. 20, 151-53. http://dx.doi.org/10.1080/01443610062913

Dolea C, Abou Zahr C (2000). Global Burden of obstructed labor in the year 2000: version 2. Geneva: WHO.

Dutta DC, Pal SK (1978). Obstructed labour: a review of 307 cases. J Obstet Gynaecol Ind. 
$28,55-8$

Gessessew A, \& Mesfin M (2003). Obstructed Labour in Adigrat Zonal hospital, Tigray region, Ethiopia. Ethiop J. Health Dev. 17(3), 175-80

Gupta R, Porwal AK (2012). Obstructed Labour: Incidence, causes and outcome. Int J Biol Med Res: 3(3), 2185-88

Gupta N, Vaid S, Acharya V (1991). obstructed labour: A prospective clinical study of 70 cases J Obstet Gynaecol India. 41, 52-55.

Hopwood HG Jr (1982). Shoulder dystocia: fifteen years' experience in a community hospital. Am J Obstet Gynecol. 144, 162-6

Kamalajayaram, V (1993). "Obstructed labour: Analysis of 126 cases," J Obstet Gynaecol India. 43, 60-63.

Khan KS, Wojdyla D, Say L, Gulmezoglu AM, Van Look PF (2006). WHO analysis of causes of maternal death: a systematic review. Lancet. 367, 1066-74. http://dx.doi.org/10.1016/S0140-6736(06)68397-9

Randhawa, Indira, Gupta KB, \& Kanwal M (1991). "A study of prolonged labour," Journal of the Indian Medical Association. 89(6), 161-63.

Rohatgi K, Singh VK, Rajvanshi VS, Mukerji M. 1977. Study of endometrial glycogen in cases of dysfunctional uterine haemorrhage \& subfertility. J Obstet Gynaecol India. 27(6), 905-10.

Sarkar CS \& Paul SK (1990). Study of 742 cases. J Obstet Gynaecol Ind. 40, 648-652

Sahu NK, Sinha A (1990). Emergence of obstetric maneuvers in preference to cesarean section in the management of obstructed labour. J Obstet Gynaecol Ind. 40, 217-22

\section{Copyright Disclaimer}

Copyright for this article is retained by the author(s), with first publication rights granted to the journal.

This is an open-access article distributed under the terms and conditions of the Creative Commons Attribution license (http://creativecommons.org/licenses/by/3.0/). 